\title{
Interpretation and machine translation towards google translate as a part of machine translation and teaching translation
}

\author{
Vichard L. Kane ${ }^{1}$
}

ARTICLE INFO

Received: 27 September 2020

Revised: 18 October 2020

Accepted: 9 November 2020

\section{KEYWORDS}

English,

google translate,

interpretation,

machine translation,

multilanguage.

\begin{abstract}
Language comprehension is the capacity of someone to properly understand the language to fully communicate the message and details. When dialects are distinct, the problem arises. This condition can lead to misconception as understudies, particularly those whose specialty is not English, cannot gain real importance. Along these lines, interpreting is regarded as one of the suggested arrangements in this area. As the results, the message's basic significance and setting in an unknown dialect can be precisely seen in English. Interpretation is a help to resolve this language boundary for this case. Moreover, finding an individual who is accessible to decipher each and every language is found troublesome. Furthermore, the aftereffect of interpretation is by one way or another influenced and impacted by the interpreter's abilities. In this manner, interpretation application turns into the one to be depended on. A lot of online interpretation applications have been made available for the last few years. The best one is Google Translate which is a multi-lingual online computer interpretation (MT) system. It is said as a multilanguage interpretation programme, as it can decode material from over 90 dialects. It is also said that since mid2000s, Google Translate is the most popular online interpretation programme. Google Translate is the least challenging approach to view the data written in English for undergraduate studies.
\end{abstract}

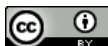

Copyright (C) 2021 by The author(s). This is an open access article distributed under the terms of the Creative Commons Attribution (CC BY 4.0), which permits unrestricted use, distribution, and reproduction in any medium, as long as the original authors and source are cited. No permission is required from the authors or the publishers.

\footnotetext{
$\checkmark$ New York University, New York, United States
} 


\section{INTRODUCTION}

Interpretation can be defined as leading a move to intervene in an objective language from a source language [1][3]. Similarly, perception is a way of transferring the value from a source language to a receiving language from a fundamental level, which is elaborated and semantically performed in order to fulfil the proportional articulation in the receptor language [5]. At that point, interpretation means repeating the ordinary, closing terms of similarity from the source language to the target or the receptor language by thinking about the first message and design.

The most important thing to understand this principle is to translate into the objective language from the source language or the first material, which has similar significance by continuing to change the style into the current objective language so that the outcome is just as general. Those three angles; source language text, target language text, and context during the interpretation process are therefore indivisible points of view. They have to type, reorder words or phrases inside the Google Translate page box and instantly an explanation result will be available in a moment. Google Translate serves as the quickest interpretation and it assists to any electronic stage for whatever length of time that there is web network. Initially, it appears to be so natural to do so. In any case, there are numerous interesting points about Google Translate [7][9].

Comprehensively, Google Translate is a computer interpreter that disciplines words that rely on its database. By comparison, language is a system organized on basic criteria. The problem is that often Google Translate couldn't follow particular language's syntactic expectations. A few investigations have been performed, showing that the degree of its accuracy is still flawed.

\section{MATERIALS AND METHODS}

The procedure of interpretation includes a few stages. They are breaking down the source text, moving the significance of source text into the objective content, and the latter is rebuilding the content into the objective language which is dependent on its alteration. Moreover, a deeper interpretation process is supposed to lead another process that tries the outcome of the interpretation. Checking the outcome of the interpretation is commendable in order to verify and maintain correct interpretation in importance and style. Checking or reinvestigating the result is notable because finding the inference that actually equals source language words is very difficult [11]. This is because of the distinctive arrangement of the two dialects. In addition, an interpreter system in giving interpretation additionally gets one of the greatest viewpoints that impact the proportionate word that is utilized. Interpreter's inclination in utilizing foreignization and training in deciphering certain writings has noteworthy impact in the content [13]. The moment this problem arises, it must be possible to try, identify and test the comparable terms containing the closest value to the first structure to ensure that it is correct. The closest normal is therefore the most suitable word for interpretation. Identicality is a condition where the selected terms can be read from the source. Proportionality doesn't concern the exact definition, but it becomes the best substitute for the words interpreted. Whatever be the case, it is definitely not an easy job to interpret how all is accomplished after equality has been achieved. Each result of interpretation is required to satisfy the need for a decent interpretation to qualify [15].

The outcome of perception is ideal when the three necessities, specifically accuracy, consistency or consistency and expectation, are met [17]. Interpretation is correct when a message or thinking of source language text is moved into objective language text and recreated as exactly as possible. Interpretation is obvious when the value of the source language text is communicated by the intended target language text topic promptly and totally justifiable. This view here and there is generally taken as an open interpretation. In conclusion, interpretation is regular when the style or structure used in the target language text is the normal direction as well as imaginable yet relevant to the source text. The role of comparability is taken into account in this regard. In reality, considering these perfect prerequisites of interpretation is a perplexing procedure for an interpreter. That is the reason why interpretation may take some long occasions to be finished. Notwithstanding, the quick interest of interpretation brings about creating advances that can help human interpretation.

It is natural that creativity will ease the perception process and disengage it. The new interpretation breakthrough is known as machine translation (MT, hereafter). MT is a computer phonetic that uses explicit programming to decrypt text from one language to another [19]. The use of MT means that the interpretation movement must be done by the computer. For a considerable length of time, MT acquire consideration, as it increments its accessibility of registering power, phonetic information and the developing requirement for robotization after arrangements of semantic principles which were physically included by etymologists and interpreter for every language pair [21]. As this interpretation machine is satisfied with the accessibility of human interpretation knowledge, it results in different interpretation styles that impact the current interpretation pattern. 
The appeal of interpretation prerequisite in any area due to trade, globalization of correspondence, overall business and so on seeks progress in cutting-edge computer interpretation.

\section{RESULTS AND DISCUSSIONS}

As a matter of fact, the general job of machine interpretation should help; conceivably the human interpretation to give the objective language text to meet the perfect interpretation. Eluding this, MT is an amazing support as it serves a range of technologies that are used to ease, streamline and reduce interpretation costs. As MT is called a complete translator, it experiences an exceptional arrangement of difficulty in altering context and seeking proportionality, because human language is a frame of mind and requires complex angles [23]. Some past examinations have focused on machine interpretation assessments and have shown that it is not as proper as human [25]. In many cases, a few investigations likewise demonstrated that the interpretation consequence of MT is commendable, especially as the emergency treatment in unknown dialect learning [27]. This is far from the true condition and shows that a more profound examination concerning the utilization of MT is yet required. This is likewise bolstered by the current circumstance wherein the utilization of MT is essentially incremented as it is shown by the quick utilization of a few applications that give a momentous interpretation. The advancement of the Web gives a solid impact to the improvement of MT. Google Translate is one of the most developed machine interpretations which runs in the present time. Today, it is regarded as the most popular machine interpretation because people prefer to look for MT in comparison to real human interpretation [29]. It showed that machine perception has a significant role to play in interpreting.

The computer interpretation improvement is ahead of schedule. The immense progress by the computer builder in comparison to his first encounter in the 1930s was seen [2]. One of these is Google Translate, one of the most remarkable computer interpretations. Google Translate is a Google company created by electronic maker-free interpretation that provides texts translated from one language to the next in a wider range of dialects (around more than 90 dialects) [4]. It is widely said that Google Translate has become the shortest route to understanding.

As clarified in the previous section, interpretation requires a progression period in unraveling and encoding the language. It also contains a few interpretation periods for Google Translate. Google Translate is previously called a predictive translation machine in which Google Translate uses its online knowledge base calculation independently in order to determine its meaning during the interpretation period. When it is necessary to decode a book, Google Translate looks at any structure of composite material contained in the web and looks for the same example of interpretation. From now on, the computer takes the most comparable example its importance and places it on its source text as clear phrases. It is also said that Google Translate can only decode a similar example that is accessible on the Internet [6]. Google has posted in 2016 on its new framework known as the Google Neural Machine Translation Framework. It is another paradigm for machine interpretation based on artificial neural networks and deep learning. These two pillars are considered to be a crucial contrast between procedures for human and simple machine interpretations. Google announced another new framework in the blink of an eye, Zero-Shot Translation with the multi-lingual machine translation system of Google. This mechanism should be able to maintain a strategic distance from an irregular perception of its supposed consequences. This progress is said to be a completely unbelievable one because it clearly demonstrates an advancement to make computers get semantics and consequences, not uncomplicated syntactic word mapping and phrases between specific language sets [8].

Regardless of the development, advancement and improvement of Google Translate, the aftereffect of its interpretation is very easily proven wrong. It might be the humble machine interpretation, however in certain focuses; it bombs in perceiving a few examples of language, for example, subjectaction word understanding, extraordinary terms of a few fields, in length, complex sentences, and so forth [10]. Like some other bits of innovation or application, Google Translate likewise experience a few concerns. To start with, Google Translate is unreservedly used by everybody for many reasons, not only the language learning. For this situation, individuals are easy yet pointless in engrossing the entire significance of the language. This worry may turn into an incredible arrangement when understudies who are not majoring English utilize this gadget and the content evidently proves with no serious help. In addition, since this innovation is totally utilized, any individual who is not even in the interpretation field may alter or change the inclination in the application. The more regrettable is that the improper interpretation result can be altered by anybody and may show up when somebody types the word. Since there is no amendment upon the altered words, it is hard for an average citizen to change the importance. Indeed, it might prompt a misconception over a language [12].

\section{Google Translation}

The last part has thoroughly explained the essence of the Google Translation performance. Although it is very easy to refute, in any case Google translation findings can be recognized for language learning, in particular educational 
interpretation. Interpretation is an inevitable feature of language education. As a first experience, both teacher and student are highly likely to include the use of Google Translation in their education and learning steps, since they are the simplest way to provide interpretation. With regard to this opportunity, and referring to the essence of the results of Google Translation, it is important to analyze Google Translation results and use them in training interpretations. The analysis is limited to evaluating the Google Translation results and their use in the instructional interpretation, which is firmly reflected by the Google Translation results and educational interpretation sections.

In unknown dialect learning, interpretation assumes a significant part since it assists understudies with improving their language understanding. A legitimate clarification of interpretation cycle should ignore the understudies so that they can separate the language viewpoint as they are learning it. Instructing interpretation requires the educator to give certain interpretation procedures the literature may decide to utilize. Besides, these techniques should assist understudies with improving their profile as understudy interpreter. Having great perusing capacity in an unknown dialect, having sufficient information regarding the matter, having affectability to both source and target language, and having capability to compose the objective language carefully, obviously, and precisely are a few rules of good interpreter. This especially become the goals of instructing interpretation that ought to be refined by understudies whenever it is directed [14]. Instructing interpretation is certifiably not a basic errand, even it is more perplexing than single interpretation movement. During this cycle, understudies have instructed a few parts of language in deciphering text to be of specific state of text, kinds of mentality, demeanor engraves, methodology of talk, with means and significances, noteworthy assets, author's perspective, and tone and disposition.

These various viewpoints expect instructor to give the understudies a proper interpretation methodology so that they can change the significance, locate the nearest comparability and finally produce a precise interpretation result. Remembering this idea, one of the most improper use of Google Translate in promoting comprehension is that it cannot train understood what strategies to use as well as separate language angles. While Google Translate tries to build a higher innovation to achieve results as closely as human comprehension, Google Translate bombs perceive language atmosphere and attitude. Also, Google Translate normally comes up short at perceiving the example with regards to extraordinary term of explicit field. Single word may have a few equivalences in another dialect, and the nearest proportionality dependent on the setting is one that ought to be picked and changed in interpretation. For this situation, Google
Translate may replicate the words implying that drives have distinctive understanding contrasted with its unique importance. Hence, the utilization of Google Translation brings about instructing interpretation might be commendable when it is utilized as the primary experience in discovering a couple of new words during the exercise. In any case, with regards to propel learning, Google Translation result at this point might not be proper except if it is helped with human interpretation subsequently leading to exhaustive investigation. This outcome is in accordance with the consequence of past examination that discovered a few imperfections in machine interpretation and need in helping the interpretation's outcome [16].

Dozens of English translations of the Qur'an are available in bookstores and online. Periodically we hear of a new translation of the Qur'an, drawing on the previous translations and making some changes. In fact every translation is a reflection of how the translator understands the Qur'an based on his subjective reading and sectarian or political orientation. Below we will provide examples of the translations of the Qur'an produced in the twentieth century.

One of the most widely used translations in America is Mohamed Ali's translation titled The Holy Qur'an, published in 1917. This translation supports the Ahmadi creed in rejecting miracles and the miraculous birth of Jesus as well as the reference to Prophet Muhammad as the final prophet [18]. This translation was adopted by the Nation of Islam led by Louis Farrakhan in America.

Influenced by Mohamed Ali, Pickthall translated the Qur'an to remedy perceived problems of translations that had been produced by Christian missionaries. Although his translation, published in 1930, was almost free of extra commentaries, "[h]e adopted Muhammad Ali's bias against descriptions of miracles and argued, for example, that the Qur'anic description of Muhammad's night voyage to the heavens was just a vision" [20].

Abdullah Yusuf Ali's translation published in 1934 was the most widely used English translation produced by a Sunni Muslim until 1995 when Alhilali and Khan published their translation. His translation was heavily embellished with exegetical glosses and footnotes derived from early exegetical works. In addition, "some of his copious notes, particularly on hell and heaven, angels, jinn and polygamy, etc., are informed with the pseudo-rationalist spirit of his times" [22].

In an attempt to avoid exegetical explanations, Mohamed Asad drew on his own modern thinking in translating the Qur'an. He ended up denying some Islamic miracles. "Asad denies the occurrence of such events as the throwing of Abraham into the fire, Jesus speaking in the cradle, etc. He also regards Luqman, 
Khizr and Zulqarnain as 'mythical figures' and holds unorthodox views on the abrogation of verses" [24].

It was adopted the Sunni worldview in translating the Qur'an by heavily relying on three works of exegesis: Tabari, Qurtubi and Ibn Kathir. Their translation, which is called The Noble Qur'an, is widely distributed among Sunni Muslims for adopting an orthodox approach to Allah's attributes, confirming all the literal readings of miracles and incorporating explanatory notes. However, the extensive glosses derived from the exegetical works may exclude other possible interpretations.

Lalah Bakhtiar presented a new translation of the Qur'an that considers the gender of the speaker. She attached the feminine marker (f) to all gender-neutral words in English which have animate feminine references in the source text throughout the Qur'an. She noted, just as I found a lack of internal consistency in previous English translations, I also found that little attention had been given to the woman's point of view. So when words in a verse refer directly to a woman or women or wife or wives and the corresponding pronouns such as (they, them, those), I have placed an (f) after the word to indicate the word refers to the feminine gender specifically. Otherwise, in the Arabic language (as in Spanish), the masculine pronoun may be used generically to include both male and female human beings.

Bakhtiar adopted a feminine approach in translating the Qur'an to give more presence to women and ensure equality between the two genders. She even translated some verses that are seen today by some Westerners as an injustice and encroachment of the woman's rights, such as the issue of beating a rebellious wife. Let us have a look at the following Qur'anic verse: Men are supporters of wives because God has given some of them an advantage over others and because they spend of their wealth. So the ones (f) who are in accord with morality are the ones (f) who are morally obligated, the ones (f) who guard the unseen of what God has kept safe. But those (f) whose resistance you fear, then admonish them (f) and abandon them (f) in their sleeping place, then go away from them (f); and if they (f) obey you, surely look not for any way against them (f); truly God is Lofty, Great.

The word idribuhnna "beat them," which is understood by the majority of Muslims as symbolic beating, i.e. beating which does not break a bone or leave a mark, is rendered as "go away from them". Although we have many translations of the Qur'an, there is still room for modification and revision, as the Qur'an itself is inimitable linguistically, scientifically and legislatively according to the Islamic point of view. Also, Muslims believe that the Qur'an is unique in style and unexcelled in beauty, and has incessantly renewable meanings.
In this sense, the Qur'an should be translated by every generation to make it discernible to the new audience because the network of relations according to the polysystem theory changes from time to time and from one community to another.

\section{Poly System Theory}

Before the 20th century closed, we heard some voices in translation that called for a more integrated approach to the source and target texts, considering both of them as part of a much wider social and cultural context. Proposed by EvenZohar, poly system theory addresses the translated text as a system in its own that should be described within other network of relations that interact with each other, be it literary, social, historical, cultural, etc. Here translation studies moves from prescriptive approaches to a less prescriptive scope. Even defined a system as "the network of relations that can be hypothesized for a certain set of assumed observables 'occurrences'/'phenomena')."

For instance a novel cannot be studied apart from other literary genres, and literary work in general is part of a wider framework that is informed by social, historical, cultural and literary practices and perspectives. The translated literary work is a system in its own right that has an interrelated network of relations. Authors, translators, publishers, readers and so forth are unpredictable variables who do not write, translate, publish, read or buy books in a social, cultural or historical vacuum. The source texts and translations are informed and influenced by a set of interrelated systems or factors that interact with one another to shape the final form of the work at play, be it original or translation. Therefore, polysystem theory proposes that a polysystem of an original text or a translation consists of a number of systems (literary, social, cultural, historical, etc.). For example, children's literature is a system and is linked to other literary systems as well as social, cultural, and historical systems.

To sum up, "Even-Zohar's polysystem theory moves the study of translations out of a static linguistic analysis of shifts and obsession with one-to-one equivalence and into investigation of the position of translated literature as a whole in the historical and literary systems of the target culture" [26].

The use of commentaries of specific authors in understanding the meaning of the Qur'an will exclude other literary and nonliterary systems, i.e., other linguistic and extra-linguistic contributions made by their contemporary authors in all scholarly fields like theology, hadith, medicine, physics, literature, and so forth. Therefore, to analyze the verses selected for this study, we will use more representative data produced at the early and late periods of Islam. This list includes a number of controversial verses that have different 
readings within the community of the source language. The controversy is mirrored subsequently on the choices of the translators of the Qur'an later on. Because the list is long and cannot be adequately analysed in this paper, three verses are selected to show the implications of three contextual settings: social, theological and legal.

Between the early and late periods of Islam is a very long lapse of time that spans over ten centuries from the first/seventh century until the present time. Although the Classical Arabic remains understandable throughout that course of time, yet the social and cultural context has changed dramatically. The practices, concerns and needs of people have been colored by the different religious, political and social powers that controlled Muslim lands. Therefore, we need to understand the network of relations in the early period and then how the text is received by later generations.

To study the early context, I collected a corpus of the early Classical Arabic extending over the first four centuries of Islam that is until the early eleventh century (Gregorian calendar). The works I included are mainly books. I also gathered some short poems written by one poet into a collection and I treated them as a text. The time span of these writings starts as early as the advent of Islam up to the end of the eleventh century. This five million word Classical Arabic corpus was assembled has the following features:

1) It is an electronic corpus; this makes investigating Arabic a more accurate and faster process.

2) It is balanced; it covers a wide scope of written Arabic texts to be used for more than one purpose.

3) More importantly, this corpus is synchronic, dealing with only one variety of Arabic along a particular span of time, i.e. early Classical Arabic. This can make the study based on it more consistent and more methodical.

This corpus provides the translators of the Qur'an with a balanced account of the Arabic language. In other words, instead of relying on one source (exegesis) or one author (exegete), they will have access to the way the language is understood and used in most genres, including the Qur'an and its exegesis. The modern corpus "Arabi Corpus" is a freelyaccessed 173,600,000 word corpus with a user-friendly interface posted online, developed and maintained by Dilworth Parkinson at Brigham Young University, Provo, Utah. ${ }^{2}$ This corpus allows users to search large raw corpora for words, structures and grammatical patterns. Information about word frequency, collocation, regular expressions and lexical behavior of words and phrases can also be extracted.

${ }^{2} \mathrm{http}: / /$ arabicorpus.byu.edu.

Kane, V. L. (2020). Interpretation and machine translation towards google translate as a part of machine translation and teaching translation. Applied Translation, 15(1), 10-17. https://doi.org/10.51708/apptrans.v15n1.1337
To examine the network of relations of the Qur'an using the extended version of the poly system theory, corpus linguistics techniques were used and a model was designed to meet the different systems of the early and late generations. The model consists of three stages and each stage involves a number of systems.

The first stage involves a linguistic analysis of the case under investigation. This would include the different linguistic levels, starting from the lowest in the linguistic hierarchy, the individual units of sound. Then we move up the linguistic cline to deal with words, phrases, sentences, and discourse. Hence, the translator may become more proficient in approximating the source language patterns and styles to the target language audience. The linguistic analysis also includes the ways of reciting the Qur'an, because some words in the Qur'an that are uttered differently by scholars of Qur'an recitations might inform the overall meaning. The context should also be considered to understand the linguistic relationship that holds between a word, expression or sentence and the entire text. Accordingly, what comes before and after a given a word or a phrase is vital in drawing up the overall meaning. Also, texts of similar characteristics or describing the same value or issue or recounting the same story or parable should be aggregated with each other. "meaning... is to be regarded as a complex of semantics each handles its own components of the complex in its appropriate context." The importance of context in translation is illustrated [28], who propose three dimensions of context: (1) the communicative dimension which involves the user (idiolect, dialect, etc.) and the use (field, mode, tenor, etc.); (2) the pragmatic dimension comprising "the study of the relations between language and its context of utterance" and is determined by speech acts, implicatures, presuppositions, etc.; and (3) the semiotic dimension involving aspects such as word, text, discourse and genre-such aspects constitute signs, as well as intertextuality.

The early context of an utterance refers to the way the early generation of Muslims received and understood it. The context in the previous stage refers to the linguistic context. Here, the context is related to extralinguistic relationships, socially, culturally, temporally, spatially, and so forth. It defined the term "context" as "the set of premises used in interpreting an utterance ... a subset of the hearer's assumptions about the world." They point out that "a context in this sense is not limited to information about the immediate physical environment or the immediately preceding utterances: expectations about the future, scientific hypotheses or religious beliefs, anecdotal memories, general cultural assumptions, beliefs about the mental state of the speaker, may all play a role in interpretation" Accordingly, the translator of the Qur'an should examine the socio-historical context, worldviews of the contextual relations, and phonetics, grammar, lexicology, and 
early generations, and the narrative, ethical, legal and theological purposes of the intended message. This also involves whether the message is ultimately addressing a specific issue that took place in the early period upon which a Divine utterance was revealed, or whether the utterance is general, fitting all times and places [30].

\section{CONCLUSION}

An analysis of the modern context brings to light the contemporary practices, concerns and needs of the later generation of Muslims. In this stage, one can replicate the contextual analysis employed in the previous stage for the modern era. In other words, this stage addresses the extralinguistic relationships, socially, culturally, temporally, and spatially. Then it involves an analysis of the present context vis-à-vis the socio-historical context. An analysis of the selected verses in eighteen translations of the Qur'an reveals the systems relating to the modern context and those relating to the early context. The consideration of both types of systems may help the translator of the Qur'an have an overall picture of the situation in both eras and may come up with an approach that more or less fits both contexts. To show the validity of the model proposed in this paper, three verses are selected for analysis. These verses relate to extra-linguistic and sociohistorical factors in both eras, involving social, theological and legal factors.

\section{Conflict of Interest Statement}

The authors declare no conflicts of interest related to the material presented in this article.

\section{REFERENCES}

[1] Amancio, D. R., Nunes, M. D. G., Oliveira Jr, O. N., Pardo, T. A. S., Antiqueira, L., \& Costa, L. D. F. (2011). Using metrics from complex networks to evaluate machine translation. Physica A: Statistical Mechanics and its Applications, 390(1), 131-142. https://doi.org/10.1016/j.physa.2010.08.052

[2] Balahur, A., \& Turchi, M. (2014). Comparative experiments using supervised learning and machine translation for multilingual sentiment analysis. Computer Speech \& Language, 28(1), 56-75. https://doi.org/10.1016/j.csl.2013.03.004

[3] Banik, D., Ekbal, A., Bhattacharyya, P., \& Bhattacharyya, S. (2019). Assembling translations from multi-engine machine translation outputs. Applied Soft Computing, 78, 230-239. https://doi.org/10.1016/j.asoc.2019.02.031
[4] Choi, H., Cho, K., \& Bengio, Y. (2017). Contextdependent word representation for neural machine translation. Computer Speech \& Language, 45, 149-160. https://doi.org/10.1016/j.cs1.2017.01.007

[5] Choi, H., Cho, K., \& Bengio, Y. (2018). Fine-grained attention mechanism for neural machine translation. Neurocomputing, 284, 171-176. https://doi.org/10.1016/j.neucom.2018.01.007

[6] Costa-Jussa, M. R., \& Fonollosa, J. A. (2015). Latest trends in hybrid machine translation and its applications. Computer Speech \& Language, 32(1), 3-10. https://doi.org/10.1016/j.csl.2014.11.001

[7] Costa-jussà, M. R., Allauzen, A., Barrault, L., Cho, K., \& Schwenk, H. (2017). Introduction to the special issue on deep learning approaches for machine translation. Computer Speech \& Language, 46, 367-373. https://doi.org/10.1016/j.csl.2017.03.001

[8] Dew, K. N., Turner, A. M., Choi, Y. K., Bosold, A., \& Kirchhoff, K. (2018). Development of machine translation technology for assisting health communication: A systematic review. Journal of biomedical informatics, 85, 56-67. https://doi.org/10.1016/j.jbi.2018.07.018

[9] Dorr, B. J., Jordan, P. W., \& Benoit, J. W. (1999). A survey of current paradigms in machine translation. Advances in computers, 49, 1-68. https://doi.org/10.1016/S0065-2458(08)60282-X

[10] Firat, O., Cho, K., Sankaran, B., Vural, F. T. Y., \& Bengio, Y. (2017). Multi-way, multilingual neural machine translation. Computer Speech \& Language, 45, 236-252. https://doi.org/10.1016/j.csl.2016.10.006

[11] Germann, U., Jahr, M., Knight, K., Marcu, D., \& Yamada, K. (2004). Fast and optimal decoding for machine translation. Artificial Intelligence, 154(1-2), 127143. https://doi.org/10.1016/j.artint.2003.06.001

[12] Gulcehre, C., Firat, O., Xu, K., Cho, K., \& Bengio, Y. (2017). On integrating a language model into neural machine translation. Computer Speech \& Language, 45, 137-148. https://doi.org/10.1016/j.cs1.2017.01.014

[13] Harrat, S., Meftouh, K., \& Smaili, K. (2019). Machine translation for Arabic dialects (survey). Information Processing \& Management, 56(2), 262-273. https://doi.org/10.1016/j.ipm.2017.08.003

[14] Hutchins, W. J. (1995). Machine translation: A brief history. In Concise history of the language sciences (pp. 431-445). Pergamon. https://doi.org/10.1016/B978-0-08042580-1.50066-0

[15] Madankar, M., Chandak, M. B., \& Chavhan, N. (2016). Information retrieval system and machine translation: a review. Procedia Computer Science, 78, 845-850. https://doi.org/10.1016/j.procs.2016.02.071

[16] Moussallem, D., Wauer, M., \& Ngomo, A. C. N. (2018). Machine translation using semantic web technologies: A 
survey. Journal of Web Semantics, 51, 1-19. https://doi.org/10.1016/j.websem.2018.07.001

[17] Navigli, R., \& Ponzetto, S. P. (2012). BabelNet: The automatic construction, evaluation and application of a wide-coverage multilingual semantic network. Artificial intelligence, 193, 217-250. https://doi.org/10.1016/j.artint.2012.07.001

[18] Pecina, P., Dušek, O., Goeuriot, L., Hajič, J., Hlaváčová, J., Jones, G. J., ... \& Urešová, Z. (2014). Adaptation of machine translation for multilingual information retrieval in the medical domain. Artificial intelligence in medicine, 61(3), 165-185. https://doi.org/10.1016/j.artmed.2014.01.004

[19] Peris, Á., \& Casacuberta, F. (2019). Online learning for effort reduction in interactive neural machine translation. Computer Speech \& Language, 58, 98-126. https://doi.org/10.1016/j.csl.2019.04.001

[20] Peris, Á., Domingo, M., \& Casacuberta, F. (2017). Interactive neural machine translation. Computer Speech \& Language, 45, 201-220. https://doi.org/10.1016/j.csl.2016.12.003

[21] Petrucci, G., Rospocher, M., \& Ghidini, C. (2018). Expressive ontology learning as neural machine translation. Journal of Web Semantics, 52, 66-82. https://doi.org/10.1016/j.websem.2018.10.002

[22] Su, J., Zhang, X., Lin, Q., Qin, Y., Yao, J., \& Liu, Y. (2019). Exploiting reverse target-side contexts for neural machine translation via asynchronous bidirectional decoding. Artificial Intelligence, 277, 103168. https://doi.org/10.1016/j.artint.2019.103168

[23] Tan, Z., Su, J., Wang, B., Chen, Y., \& Shi, X. (2018). Lattice-to-sequence attentional Neural Machine Translation models. Neurocomputing, 284, 138-147. https://doi.org/10.1016/j.neucom.2018.01.010

[24] Wang, D. (2009). Chinese to English automatic patent machine translation at SIPO. World Patent Information, 31(2), 137-139. https://doi.org/10.1016/j.wpi.2008.10.003

[25] Wołk, K., \& Marasek, K. (2015). Neural-based machine translation for medical text domain. based on european medicines agency leaflet texts. Procedia Computer Science, 64, 2-9. https://doi.org/10.1016/j.procs.2015.08.456

[26] Xiao, T., Zhu, J., \& Liu, T. (2013). Bagging and boosting statistical machine translation systems. Artificial Intelligence, 195, 496-527. https://doi.org/10.1016/j.artint.2012.11.005

[27] Xiao, Y., Keung, J., Bennin, K. E., \& Mi, Q. (2018). Machine translation-based bug localization technique for bridging lexical gap. Information and Software Technology, 99, https://doi.org/10.1016/j.infsof.2018.03.003
[28] Yang, B., Wong, D. F., Chao, L. S., \& Zhang, M. (2020). Improving tree-based neural machine translation with dynamic lexicalized dependency encoding. KnowledgeBased Systems, 188, 105042. https://doi.org/10.1016/j.knosys.2019.105042

[29] Yang, Y., \& Wang, X. (2019). Modeling the intention to use machine translation for student translators: An extension of Technology Acceptance Model. Computers \& Education, 133, 116-126. https://doi.org/10.1016/j.compedu.2019.01.015

[30] Yang, Z., Chen, W., Wang, F., \& Xu, B. (2018). Generative adversarial training for neural machine translation. Neurocomputing, 321, $146-155$. https://doi.org/10.1016/j.neucom.2018.09.006 